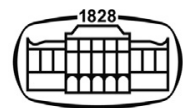

AKADÉMIAI KIADÓ

\title{
Attention deficit hyperactivity disorder and gaming disorder: Frequency and associated factors in a clinical sample of patients with Gaming Disorder
}

Journal of Behavioral Addictions

10 (2021) 4, 1061-1067

DOl:

$10.1556 / 2006.2021 .00074$ (c) 2021 The Author(s)
BRIEF REPORT

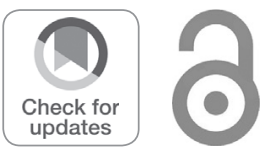

${ }^{*}$ Corresponding author. Email: clemence.cabelguen@ chu-nantes.fr

\author{
CLÉMENCE CABELGUEN $^{1 *}$ (1), BRUNO ROCHER ${ }^{1}$ (1),

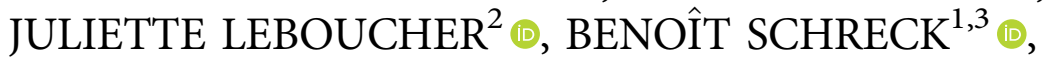 \\ GAËLLE CHALLET-BOUJU ${ }^{2,3}$ (0), \\ JEAN-BENOÎT HARDOUIN ${ }^{3}$ (1) and \\ MARIE GRALL-BRONNEC ${ }^{1,2,3}$
}

\footnotetext{
${ }^{1}$ Department of Addiction Science and Liaison Psychiatry, Nantes University Hospital, Nantes, France

${ }^{2}$ Clinical Investigation Unit "Behavioral Addictions/Complex Affective Disorders", Addictology and Psychiatry Department, Nantes University Hospital, Nantes, France

${ }^{3}$ SPHERE, Inserm 1246, University of Nantes and Tours, Nantes, France
}

Received: January 28, 2021 • Revised manuscript received: July 30, 2021; September 17, 2021 • Accepted: October 3, 2021

Published online: October 26, 2021

\begin{abstract}
Background and aims: Since June 2018, gaming disorder (GD) has been recognized as a disease. It is frequently associated with attention deficit hyperactivity disorder (ADHD), as there are common vulnerability factors and bidirectional interactions between the two disorders. This study aims to evaluate the presence of ADHD symptoms and predictive factors of ADHD among patients with GD. Methods: Ninety-seven patients $\geq 16$ years old referred to the University Hospital of Nantes between 2012 and 2020 for GD were included. The diagnosis of GD was given a posteriori in accordance with the new ICD-11 GD definition. ADHD was screened using the Adult-ADHD Self-Report Scale and the Wender-Utah Rating Scale. A multivariate logistic regression model was used to identify explanatory factors for ADHD-GD comorbidity. Results: The rate of GD patients who screened positive for ADHD was $39 \%$. Predictive factors of ADHD-GD comorbidity were impulsivity (higher score on the negative urgency dimension) and low self-esteem. Discussion: The rate of ADHD found among patients with GD is consistent with that from the literature on internet GD but higher than that found for other behavioural addictions. The identification of a higher negative urgency score and low self-esteem as predictive factors of AHDH-GD comorbidity indicates that gaming could be considered a dysfunctional way to cope with emotional dysregulation in ADHD or to virtually escape. Conclusions: Comorbid ADHD must be taken into consideration to minimize its functional impact on GD patients and gamingrelated damage. In contrast, the evaluation of gaming habits in patients with ADHD could be useful for both prevention and care.
\end{abstract}

\section{KEYWORDS}

ADHD, gaming, addiction, ICD-11 criteria, impulsivity

\section{INTRODUCTION}

In 2013, internet gaming disorder (IGD) was integrated into the $5^{\text {th }}$ edition of the Diagnostic and Statistical Manual (DSM-5) (American Psychiatric Association, 2013). Since June 2018, the World Health Organization (WHO) has recognized gaming disorder (GD) as a stand- 
alone diagnosis in the 11th version of the International Classification of Diseases (ICD-11) (World Health Organization, 2019). GD is defined by 3 criteria: (1) impaired control over gaming; (2) increasing priority given to gaming over other activities to the extent that gaming takes precedence over other interests and daily activities; and (3) continuing or escalating gaming despite the occurrence of negative consequences. The behaviour pattern must be of sufficient severity to result in significant impairments in personal, family, social, educational, occupational or other important areas of functioning and normally evident for at least 12 months. In comparison with IGD, the criteria of tolerance, withdrawal, symptom preoccupation, concealing the time spent gaming or gaming as a way to relieve negative moods were not included in the ICD-11. Thus, the choice of either the DSM-5 or ICD-11 definition of the disorder may influence prevalence estimates.

A review of the literature analysing data from 27 worldwide studies reports a prevalence of IGD of approximately 4.7\% (Feng, Ramo, Chan, \& Bourgeois, 2017). The recent appearance of GD in international nomenclatures (ICD-11) means that prevalence data have not yet been collected.

Several risk factors for excessive gaming (online or not) have been identified (González-Bueso et al., 2018; Schou Andreassen et al., 2016). Sociodemographic factors included male sex, early age, single-parent family and maltreatment. Clinical factors include mood and anxiety disorders. Finally, psychopathological factors include impulsivity, withdrawal, reduced social and empathic skills, difficulties in emotional regulation, and attention problems. The influence of these factors on gaming is likely bidirectional (Gentile et al., 2011).

Attention deficit/hyperactivity disorder (ADHD) is a neurodevelopmental disorder (American Psychiatric Association, 2013) characterized by a clinical triad of inattention, hyperactivity and impulsivity to varying extents. In 2018, González-Bueso et al. conducted a systematic review of 53,889 children and adults in the general population worldwide. Among the 24 included studies, only 8 used ADHD measurements, with an association between ADHD and IGD found in 7 of them (González-Bueso et al., 2018). In 2017, Yen et al. conducted a cross-sectional study on 174 adults aged 20-30 years old in Taiwan suffering from GD and found that the prevalence was $39 \%(\mathrm{OR}=13.5)$ (Yen et al., 2017). Another cross-sectional study found a $32.2 \%$ prevalence among internet addict students aged 18-27 years old in Taiwan $(\mathrm{OR}=4.5)(\mathrm{Ko}, \mathrm{Yen}, \mathrm{Chen}, \mathrm{Chen}, \& \mathrm{Yen}$, 2008). Measurements of ADHD can nevertheless be biased by the use of various screening or diagnostic tools. In the review of González-Bueso et al. (2018), the authors used the ADHD Self-Report Scale (ASRS), the Strengths and Difficulties Questionnaire, Dupaul's ADHD scale or the ADHD DSM-IV-TR criteria. Yen et al. (2017) proposed an interview based on DSM-IV-TR criteria and assessed childhood ADHD history with the Kiddie-Schedule for Affective Disorders and Schizophrenia. Ko et al. (2008) developed a semistructured diagnostic tool for adult ADHD based on DSM-IV criteria. It is important to note that those three studies did not specifically evaluate ADHD in treatment- seeking samples. Thus, the prevalence rate may differ from studies that focus on patients seeking specific care for GD. Bias in prevalence estimates can also result from the difference between research on the complete syndrome of ADHD and research on only symptoms and to whether factors commonly associated with the disorder (e.g., increased risk in case of associated dyslexia) are considered.

To broadly analyse the link between ADHD and GD, we selected several domains of interest. On the one hand, we explored individual traits through innate abilities (e.g., temperament) or acquired abilities (e.g., self-esteem). We focused on impulsivity, which is a core feature of ADHD and a risk factor for developing behavioural addictions (Zilberman, Gal, Efrati, Neumark, \& Rassovsky, 2018). We were particularly interested in the identification of low self-esteem, which was found to be strongly associated with ADHD (Harpin, Mazzone, Raynaud, Kahle, \& Hodgkins, 2016) and is likely to interfere with gaming practice. On the other hand, we investigated social skills (Ryu et al., 2018) through relationship abilities and social anxiety.

To our knowledge, no work has studies the presence of ADHD symptoms and associated predictive factors among individuals diagnosed as pathological gamers according to the new ICD-11 definition. The analysis of factors associated with ADHD-GD comorbidity is of high importance to better identify the profiles of patients at risk for this comorbidity and to propose a more comprehensive and adjusted treatment for them. This study aims to fill this gap and analyse factors associated with ADHD-GD comorbidity.

\section{MATERIALS AND METHODS}

\section{Procedure}

Patients were recruited from the EVALuation of behavioural ADDictions (EVALADD) cohort (NCT01248767), which proposes a prospective follow-up of patients over 15.25 years old (the line separating paediatric and adult care in our hospital) initializing specific care for behavioural addiction at Nantes University Hospital, France. As part of the EVALADD procedure, patients completed a multiaxial psychological assessment through a face-to-face structured interview and self-administered questionnaires. The structured interview was conducted by trained research staff with experience with behavioural addictions. In our study, data were collected at the initiation of addictive care.

\section{Participants}

We selected 125 outpatients who were referred for excessive video game use (according to the patient him or herself or to his or her relatives) from January 2012 to January 2020. After exclusion of those who did not match the GD ICD-11 criteria or those for whom data were not exploitable, 97 patients were included in the analysis (Fig. 1). 


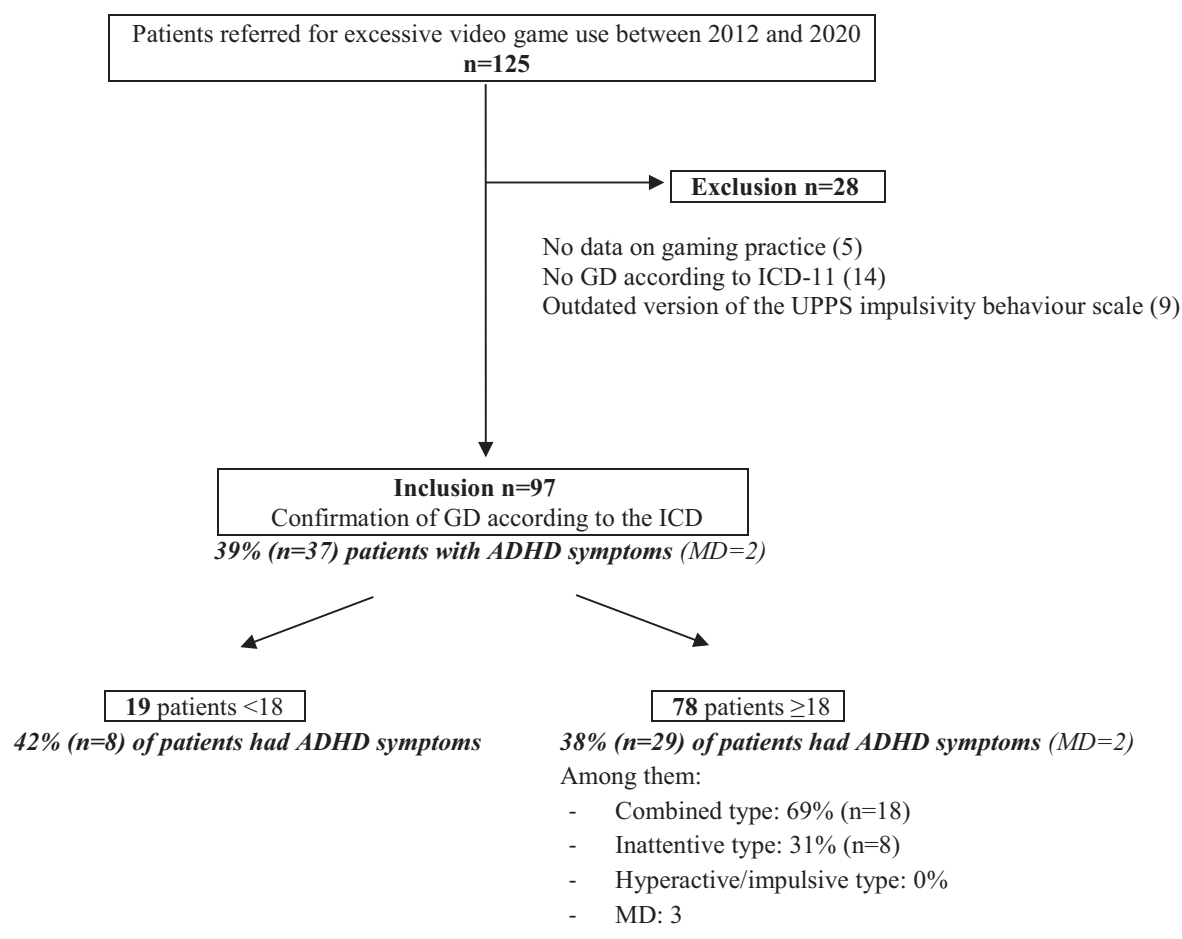

Fig. 1. Flowchart

\section{Measures}

Among the EVALADD procedures (see Fauconnier et al., 2020), only the measures specific to the domains of our study are detailed.

Gaming. A thorough investigation of the medical records of the 125 patients identified allowed us to search for the presence or absence of the three ICD-11 criteria during the 12 months preceding inclusion. Functional impairment was also systematically sought in the medical records. Only the presence of the 3 criteria and a functional impairment could lead to a diagnosis of GD and thus inclusion in the study. All cases were analysed by a researcher and the referred psychiatrist in a double-blind manner. Motives for gaming were explored using the Videogame Motivation Questionnaire (VMQ). The VMQ includes the same items and uses the same scoring system as the Gambling Motives Questionnaire (GMQ) (Stewart \& Zack, 2008), which was developed from the Drinking Motives Questionnaire (DMQ). Only the instructions differ between the GMQ and the DMQ to be appropriate for the behaviour studied. The GMQ is characterized by high internal consistency factors (alpha $=0.91$, 0.81 and 0.86 for the 3 subscales, see Stewart \& Zack, 2008). In our study, these Cronbach's alpha values were $0.76,0.73$ and 0.72 , respectively.

ADHD. Each patient completed the 25-item Wender-Utah Rating Scale (WURS), a self-administered questionnaire that retrospectively explores symptoms of ADHD during childhood on a 5-point Likert Scale (Ward, Wender, \& Reimherr, 1993). Patients $\geq 18$ years old also completed the ASRS V1.1, a screening test based on the 18 diagnostic criteria of the DSM-IV-TR (Kessler et al., 2005). To consider ADHD symptoms present, patients $<18$ years old should have a WURS score $\geq 46 / 100$. Patients $\geq 18$ years old were considered to have ADHD symptoms if they had a WURS score $\geq 46 / 100$ and a positive screening on the ASRS.

Psychopathology. Patients completed the Temperament and Character Inventory (TCI-125) (Cloninger, Przybeck, \& Svrakic, 1994), the UPPS-P impulsivity behaviour scale (Lynam, Smith, Whiteside, \& Cyders, 2006), the Rosenberg Self Esteem scale (RSE) (Rosenberg, 1965), the Liebowitz Social Anxiety Scale (LSAS) (Liebowitz, 1987) and the Relationship Scales Questionnaire (RSQ) (Griffin \& Bartholomew, 1994).

\section{Statistical analysis}

The presence of ADHD symptoms in patients with GD was estimated by a proportion calculation. The analysis of predictive factors of comorbid ADHD-GD was realized by a two-step multivariate logistic regression model. First, we selected clinically relevant variables to explain the comorbidity of ADHD-GD. Given that ADHD is a neurodevelopmental condition, we decided to focus on several traits that appear during cognitive and psycho affective development in a diachronic way. We removed redundant variables for the analysis to avoid problems with collinearity (RSE - total, LSAS - diagnosis, LSAS - fear of performance, LSAS - avoidance of performance, LSAS - fear of social interaction and LSAS - avoidance of social interaction, RSQ - preoccupied, RSQ - fearful and RSQ - dismissive). 
Selected variables were compared with bivariate tests between patients with or without ADHD symptoms (Table 1). Two-by-two comparisons were performed by means of two sample $t$-tests for quantitative variables and Chi2 or Fisher's exact tests (when appropriate) for qualitative variables. Second, variables significant at 0.20 in bivariate analyses were included in the multivariate logistic regression, and then variables nonsignificant at 0.05 were removed one at a time, starting with the least significant variable (backward procedure, Mickey \& Greenland, 1989). The corresponding odds ratios (ORs) and associated 95\% confidence intervals (95\% CIs) were estimated to quantify the strength of the association between the predictive factors selected and the characteristics of interest.

\section{Ethics}

Participants were informed of the research and provided written informed consent, including consent from parents or guardians for the participants under age 18, prior to their inclusion in the EVALADD cohort. The study was conducted in accordance with Good Clinical Practice Guidelines and the Declaration of Helsinki, with approval from the Ethics Committee in 2012, amended in 2018.

\section{RESULTS}

\section{Population characteristics}

Among the 97 included patients, 91 (94\%) were male. The average age was 23 years old $(S D=8)$. According to the
Mini International Neuropsychiatric Interview (Sheehan et al., 1998), 49\% of patients had major depressive disorder (current or past), and $26(27 \%)$ were at risk of suicide (current or past). Among anxiety disorders, social phobia was the most common, found in 21 patients (22\%). Nicotine use disorder was found in 30 patients $(31 \%)$, and alcohol and cannabis use disorders were found in 16 patients (17\%). No participant took methylphenidate, the only psychostimulant available in France for ADHD treatment.

\section{Presence of ADHD symptoms in patients with GD}

The rate of ADHD symptoms in patients with GD was estimated at $39 \%(\mathrm{SD}=5,95 \%$ CI [29-50]) (missing data (MD), $n=2$ ). Figure 1 shows the flowchart of our study and details the rates of symptoms of ADHD by patient age. These rates were $42 \%$ (95\% CI [20-64]) in patients $<18$ years old and 38\% (95\% CI [27-49]) in patients $\geq 18$ years old $(\mathrm{MD}=2)$. Among patients $\geq 18$ years old, two-thirds presented a combined type, and one-third presented an inattentive predominant type. None presented a hyperactive/ impulsive predominant type.

\section{Factors associated with ADHD-GD comorbidity}

The final multivariate logistic regression model (pseudo $\mathrm{R}^{2}$ $=0.24$ ) revealed the variables that were significantly associated with ADHD comorbidity in patients with GD: a higher score on the dimension "negative urgency" of the UPPS-P (OR $=1.5295 \%$ CI [1.25-1.85], $P<0.0001)$ and low self-esteem as estimated by the RSE (OR $=6.6095 \% \mathrm{CI}$ [1.76-24.82], $P<0.005)$.

Table 1. Clinically relevant variables to explain the comorbidity of ADHD-GD $(n=97)$

\begin{tabular}{|c|c|c|c|c|c|}
\hline & Total $(n=97)$ & $\begin{array}{c}\text { ADHD }+(n=37) \\
\text { Mean }(\mathrm{SD}) \text { or } \mathrm{n} \text { (percentage) }\end{array}$ & ADHD- $(n=58)$ & OR & $P$ \\
\hline \multicolumn{6}{|c|}{ SOCIODEMOGRAPHIC CHARACTERISTICS } \\
\hline VMQ - coping $(/ 20)$ & $15(3.5)$ & $17(3.0)$ & $14(3.4)$ & 1.279 & 0.001 \\
\hline VMQ - positive reinforcement (/20) & $15(3.1)$ & $16(3.1)$ & $14(3.1)$ & 1.142 & 0.071 \\
\hline \multicolumn{6}{|l|}{ PSYCHOPATHOLOGY } \\
\hline TCI - novelty seeking (\%) & $54(20.9)$ & $61(20.7)$ & $50(20.1)$ & 1.028 & 0.014 \\
\hline TCI - harm avoidance (\%) & $57(24.7)$ & $63(22.6)$ & $53(25.4)$ & 1.018 & 0.058 \\
\hline TCI - reward dependence (\%) & $51(17.5)$ & $50(17.3)$ & $52(17.8)$ & 0.993 & 0.570 \\
\hline TCI - persistance $(\%)$ & $32(28.0)$ & $31(30.4)$ & $33(26.5)$ & 0.997 & 0.668 \\
\hline UPPS-P - negative urgency (/16) & $10(3.1)$ & $12(3.1)$ & $9(2.5)$ & 1.421 & 0.00006 \\
\hline UPPS-P - positive urgency $(/ 16)$ & $11(2.9)$ & $12(2.8)$ & $10(2.7)$ & 1.340 & 0.0007 \\
\hline UPPS-P - lack of perseverance $(/ 16)$ & $10(3.1)$ & $11(3.2)$ & $10(2.9)$ & 1.182 & 0.023 \\
\hline UPPS-P - sensation seeking (/16) & $10(3.3)$ & $11(3.4)$ & $10(3.1)$ & 1.127 & 0.079 \\
\hline RSE - low $(<30 / 40)$ & $69(73 \%)$ & $32(87 \%)$ & $37(64 \%)$ & 3.632 & 0.020 \\
\hline LSAS - total $(/ 144)$ & $51(27.3)$ & $61(27.0)$ & $45(25.6)$ & 1.024 & 0.006 \\
\hline RSQ - secure (/25) & $15(4.4)$ & $14(4.3)$ & $16(3.5)$ & 0.896 & 0.064 \\
\hline
\end{tabular}

Variables in grey were retained to be entered in the multivariate logistic regression model (i.e., variables significant at 0.20 ). Abbreviations: Videogame Motives Questionnaire (VMQ); Temperament and Character Inventory (TCI); Urgency, Premeditation (lack of), Perseverance (lack of), Sensation seeking, Positive urgency (UPPS-P); Rosenberg Self-Esteem Scale (RSE); Liebowitz Social Anxiety Scale (LSAS); Relationship Scales Questionnaire (RSQ). 


\section{DISCUSSION}

\section{Main results}

The objective of the study was to evaluate the presence of ADHD symptoms among patients with GD diagnosed based on the new ICD-11 criteria and then to identify the predictive factors of GD-ADHD comorbidity. The rate of 39\% is similar to rates found by Yen et al., in 2017 (39.1\%) and Ko et al., in 2008 (32.2\%) among patients with IGD, despite different diagnostic tests being used. Our results are also in line with those of two other studies examined in the review of González-Bueso et al. (2018). Panagiotidi et al. (2017) found a significant correlation between the ASRS and the Problem Video-Game Playing Test in 205 healthy adults aged 27.4 years old on average $\left(R^{2}=0.22\right)$. Vadlin, Aslund, Hellström, and Nilsson (2016) identified an association between symptoms of ADHD and problematic gaming in two cohorts of 1868 and 242 Swedish adolescents in the general population aged $12-18(\mathrm{OR}=2.43,95 \%$ CI [1.44-4.11]). The results of the other studies retained by Gonzàlez-Bueso are difficult to compare with ours for several reasons: the tests used to identify ADHD symptoms were different, the sample comprised children and adults (the estimated prevalence of ADHD in children is almost twice that in adults), and study designs were of different types.

The 39\% rate of ADHD symptoms among patients with GD is particularly high compared to those of other behavioural addictions: $20-25 \%$ among patients with gambling disorder (Fatseas et al., 2016), 25\% among patients with sex addiction (Reid, Carpenter, Gilliland, \& Karim, 2011), and one-third among patients with food addiction (Davis et al., 2011). Contrary to these studies, we focused on a young, treatment-seeking sample, which limits the comparison between them. However, beyond common vulnerability factors between ADHD and diverse behavioural addictions (male sex, neurocognitive traits such as deficient inhibitory control, poor decision making and attentional bias, for example), this high prevalence could be explained by early and easy access to gaming. Moreover, gaming can enhance hyperfocus, which has been reported by many patients with ADHD (Hupfeld, Abagis, \& Shah, 2019). Video games offer an immersive experience to patients while they remain active, contrary to other addictive behaviours. This could suggest to patients that some aspects of ADHD symptomatology may be positive (Sedgwick, Merwood, \& Asherson, 2019). This comforting impression may act as a positive reinforcer of gaming and explain the choice of that addiction object for these patients.

Among the many factors evaluated as predictive of comorbid ADHD-GD, only high negative urgency and low self-esteem were significant. Persons with a marked negative urgency trait, when subjected to negative emotions, feel compelled to act immediately, in an inadequate way, to dispose of this trait (Anestis, Selby, \& Joiner, 2007). In gaming, high negative urgency has been found to be associated with problematic use of MMO-RPGs in players interviewed in cybercafés (Billieux et al., 2011). High urgency was also a characteristic found in a cluster of gamers displaying signs of problematic online gaming use (Billieux et al., 2015). Emotional dysregulation is a core feature associated with the clinical triad (inattention, hyperactivity, impulsivity) of ADHD (Shaw, ArgyrisStringaris, Joel, \& Leibenluft, 2014) and is often neglected. Among patients with $\mathrm{ADHD}$, gaming could be used to fulfil an urgent need to calm negative feelings.

Furthermore, among ADHD-GD patients, low selfesteem could lead to the use of video games to feel accomplished, to feel control, or to reassure themselves of their skills (King \& Delfabbro, 2014). It can also provide an escape from unpleasant feelings secondary to negative beliefs about themselves, or it can provide support from their gaming community.

\section{Strengths and limitations}

This study has several limitations. It is a French, singlecentre study. The cross-sectional design of our study limits the interpretation of data and exploration of the causal link between $\mathrm{ADHD}$ and GD. The sample size was small compared to those of previous studies. This feature and our design could have hindered the identification of other predictive variables of GD-ADHD comorbidity. ADHD evaluation was heterogeneous between patients $<18$ and $\geq 18$ years old. However, we decided to include younger patients to enhance the size of our sample and to increase the scope of our results. Furthermore, we used the VMQ, which is a nonvalidated scale, to explore the motives of gamers.

These limitations are compensated by the strengths of the work. We used a clinical sample of typical patients with GD (only outpatients, the large majority were male, and they were 24 years old on average at inclusion). GD was explored clinically, not via self-assessment, as commonly done in studies of gaming. The innovative nature of the study is based on the use of the new ICD-11 definition for GD. Moreover, evaluations of gaming and psychopathology characteristics were based on a clinical interview. The ASRS V1.1 and the WURS are both recommended for screening ADHD, especially in a French sample (Weibel et al., 2020). These scales, which have been mainly validated in the general population, have a higher rate of false positives in clinical samples. We were particularly stringent with patients $\geq 18$ years old with a screening estimated positive if WURS + ASRS were both positive, as we complied with the condition of use of ASRS (Kessler et al., 2005). This may have limited the risk of over screening. Nevertheless, diagnosing $\mathrm{ADHD}$ requires a clinical interview, and our procedure permitted the identification of only ADHD symptoms.

\section{CONCLUSIONS}

The rate of ADHD symptoms among patients with GD was estimated to be $39 \%$. This association opens up new clinical and therapeutic opportunities. First, the screening of ADHD in patients with GD appears essential. Conversely, a rigorous 
evaluation of video game practice in ADHD patients seems indispensable. This increased vigilance is legitimized by specific efficient care that exists for ADHD. The early identification/treatment of ADHD may help minimize its functional impact on GD patients as well as mitigate gaming-related damage. Moreover, patients suffering from ADHD and GD seem to present low self-esteem and a higher level of negative urgency, which can make them more vulnerable to mood disorders (Sowislo \& Orth, 2013) and addictive disorders (Anestis, Selby, \& Thomas, 2007), respectively. In contrast, the evaluation of video game use in ADHD patients could be useful for both prevention and care. It might be relevant for some patients with ADHD to add specific therapeutic tools targeted to GD (e.g., individual or group cognitive behavioural therapy (King et al., 2017)) to their medical care for ADHD.

Funding sources: No financial support was received for this study.

Authors' contribution: Original idea, study design: MGB, JBH. Assessments: BR, JL, GCB. Statistical analysis and interpretation of data: CC, JBH, MGB. First draft of the manuscript: CC. EVALADD cohort supervision: GCB, MGB. Contribution to the final manuscript: MGB, JBH, BR, JL, GCB, BS. Authors had full access to all data in the study and take responsibility for the integrity of the data and the accuracy of the data analysis.

Conflict of interest: Authors declare no conflict of interest.

\section{REFERENCES}

American Psychiatric Association (2013). Diagnosis and statistical manual of mental disorders (5th ed.). Washinton, DC: APA.

Anestis, M. D., Selby, E. A., \& Joiner, T. E. (2007). The role of urgency in maladaptive behaviors. Behaviour Research and Therapy, 45(12), 3018-3029. https://doi.org/10.1016/j.brat. 2007.08.012.

Billieux, J., Chanal, J., Khazaal, Y., Rochat, L., Gay, P., Zullino, D., \& Van der Linden, M. (2011). Psychological predictors of problematic involvement in massively multiplayer online roleplaying games: Illustration in a sample of male cybercafé players. Psychopathology, 44(3), 165-171. https://doi.org/10. 1159/000322525.

Billieux, J., Thorens, G., Khazaal, Y., Zullino, D., Achab, S., \& Van der Linden, M. (2015). Problematic involvement in online games: A cluster analytic approach. Computers in Human Behavior, 43, 242-250. https://doi.org/10.1016/j.chb.2014.10. 055.

Cloninger, C. R., Przybeck, T. R., \& Svrakic, D. M. (1994). The temperament and character inventory (TCI) a guide to its development and use. St. Louis, Mo: Center for Psychobiology of Personality, Washington University.
Davis, C., Curtis, C., Levitan, R. D., Carter, J. C., Kaplan, A. S., \& Kennedy, J. L. (2011). Evidence that "food addiction" is a valid phenotype of obesity. Appetite, 57(3), 711-717. https://doi.org/ 10.1016/j.appet.2011.08.017.

Fatseas, M., Alexandre, J.-M., Vénisse, J.-L., Romo, L., Valleur, M., Magalon, D., . . Grall-Bronnec, M. (2016). Gambling behaviors and psychopathology related to attention-deficit/hyperactivity disorder (ADHD) in problem and non-problem adult gamblers. Psychiatry Research, 239, 232-238. https://doi.org/10.1016/j. psychres.2016.03.028.

Fauconnier, M., Rousselet, M., Brunault, P., Thiabaud, E., Lambert, S., Rocher, B., ... Grall-Bronnec, M. (2020). Food addiction among female patients seeking treatment for an eating disorder: Prevalence and associated factors. Nutrients, 12(6). https://doi. org/10.3390/nu12061897.

Feng, W., Ramo, D. E., Chan, S. R., \& Bourgeois, J. A. (2017). Internet gaming disorder: Trends in prevalence 1998-2016. Addictive Behaviors, 75, 17-24. https://doi.org/10.1016/j.addbeh.2017.06.010.

Gentile, D. A., Choo, H., Albert, L., Sim, T., Li, D., Fung, D., \& Angeline, K. (2011). Pathological video game use among youths: A two-year longitudinal study. Pediatrics, 127(2), e319329. https://doi.org/10.1542/peds.2010-1353.

González-Bueso, V., José Santamaría, J., Fernández, D., Merino, L., Montero, E., \& Ribas, J. (2018). Association between internet gaming disorder or pathological video-game use and comorbid psychopathology: A comprehensive review. International Journal of Environmental Research and Public Health, 15(4). https://doi.org/10.3390/ijerph15040668.

Griffin, D. W., \& Bartholomew, K. (1994). Models of the self and other: Fundamental dimensions underlying measures of adult attachment. Journal of Personality and Social Psychology, 67(3), 430. https://doi.org/10.1037/0022-3514.67.3.430.

Harpin, V., Mazzone, L., Raynaud, J. P., Kahle, J., \& Hodgkins, P. (2016). Long-term outcomes of ADHD: A systematic review of self-esteem and social function. Journal of Attention Disorders, 20(4), 295-305. https://doi.org/10.1177/1087054713486516.

Hupfeld, K. E., Abagis, T. R., \& Shah, P. (2019). Living "in the zone": Hyperfocus in adult ADHD. Attention Deficit and Hyperactivity Disorders, 11(2), 191-208. https://doi.org/10.1007/ s12402-018-0272-y.

Kessler, R. C., Adler, L., Ames, M., Demler, O., Faraone, S., Hiripi, E., .. Walters, E. E. (2005). The World Health organization adult ADHD self-report scale (ASRS): A short screening scale for use in the general population. Psychological Medicine, 35(2), 245-256. https://doi.org/10.1017/s0033291704002892.

King, D. L., \& Delfabbro, P. H. (2014). The cognitive psychology of internet gaming disorder. Clinical Psychology Review, 34(4), 298-308. https://doi.org/10.1016/j.cpr.2014.03.006.

King, D. L., Delfabbro, P. H., Wu, A. M. S., Yim Doh, Y., Kuss, D. J., Pallesen, S., ... Sakuma, H. (2017). Treatment of internet gaming disorder: An international systematic review and CONSORT evaluation. Clinical Psychology Review, 54, 123-133. https://doi.org/10.1016/j.cpr.2017.04.002.

Ko, C. H., Yen, J. Y., Chen, C. S., Chen, C. C., \& Yen, C. F. (2008). Psychiatric comorbidity of internet addiction in college students: An interview study. CNS Spectrums, 13(2), 147-153. https://doi.org/10.1017/s1092852900016308. 
Liebowitz, M. R. (1987). Social phobia. Modern Problems of Pharmacopsychiatry, 22, 141-173. https://doi.org/10.1159/000414022.

Lynam, D. R., Smith, G. T., Whiteside, S. P., \& Cyders, M. A. (2006). The UPPS-P: Assessing five personality pathways to impulsive behavior. Technical report. West Lafayette: Purdue University.

Mickey, R. M., \& Greenland, S. (1989). The impact of confounder selection criteria on effect estimation. American Journal of Epidemiology, 129(1), 125-137. https://doi.org/10.1093/ oxfordjournals.aje.a115101.

Panagiotidi, M. (2017). Problematic video game play and ADHD traits in an adult population. Cyberpsychology, Behavior and Social Networking, 20(5), 292-295. https://doi.org/10.1089/ cyber.2016.0676.

Reid, R. C., Carpenter, B. N., Gilliland, R., \& Karim, R. (2011). Problems of self-concept in a patient sample of hypersexual men with attention-deficit disorder. Journal of Addiction Medicine, 5(2), 134-140. https://doi.org/10.1097/ADM. 0b013e3181e6ad32.

Rosenberg, M. (1965). Society and the adolescent self-image (pp. 560-562). Princeton.

Ryu, H., Lee, J.-Y., Choi, A., Park, S., Kim, D.-J., \& Choi, J.-S. (2018). The relationship between impulsivity and internet gaming disorder in young adults: Mediating effects of interpersonal relationships and depression. International Journal of Environmental Research and Public Health, 15(3). https://doi. org/10.3390/ijerph15030458.

Schou, A., Cecilie, Billieux, J., Griffiths, M. D., Kuss, D. J., Demetrovics, Z., .. Pallesen, S. (2016). The relationship between addictive use of social media and video games and symptoms of psychiatric disorders: A large-scale cross-sectional study. Psychology of Addictive Behaviors: Journal of the Society of Psychologists in Addictive Behaviors, 30(2), 252-262. https://doi. org/10.1037/adb0000160.

Sedgwick, J. A., Merwood, A., \& Asherson, P. (2019). The positive aspects of attention deficit hyperactivity disorder: A qualitative investigation of successful adults with ADHD. Attention Deficit and Hyperactivity Disorders, 11(3), 241-253. https://doi.org/10. 1007/s12402-018-0277-6.

Shaw, P., Stringaris, A., Nigg, J., \& Leibenluft, E. (2014). Emotion dysregulation in attention deficit hyperactivity disorder. The
American Journal of Psychiatry, 171(3), 276-293. https://doi. org/10.1176/appi.ajp.2013.13070966.

Sheehan, D. V., Lecrubier, Y., Sheehan, K. H., Amorim, P., Janavs, J., Weiller, E., ... Dunbar, G. C. (1998). The mini-international neuropsychiatric interview (M.I.N.I.): The development and validation of a structured diagnostic psychiatric interview for DSM-IV and ICD-10. The Journal of Clinical Psychiatry, 59(Suppl 20), 22-33 quiz 34-57. PMID 9881538.

Sowislo, J. F., \& Orth, U. (2013). Does low self-esteem predict depression and anxiety? A meta-analysis of longitudinal studies. Psychological Bulletin, 139(1), 213-240. https://doi.org/10.1037/ a0028931.

Stewart, S. H., \& Zack, M. (2008). Development and psychometric evaluation of a three-dimensional gambling motives questionnaire. Addiction (Abingdon, England), 103(7), 1110-1117. https://doi.org/10.1111/j.1360-0443.2008.02235.x.

Vadlin, S., Åslund, C., Hellström, C., \& Nilsson, K. W. (2016). Associations between problematic gaming and psychiatric symptoms among adolescents in two samples. Addictive Behaviors, 61, 8-15. https://doi.org/10.1016/j.addbeh.2016.05.001.

Ward, M. F., Wender, P. H., \& Reimherr, F. W. (1993). The Wender Utah Rating Scale: An aid in the retrospective diagnosis of childhood attention deficit hyperactivity disorder. The American Journal of Psychiatry, 150(6), 885-890. https://doi. org/10.1176/ajp.150.6.885.

Weibel, S., Menard, O., Ionita, A., Boumendjel, M., Cabelguen, C., Kraemer, C., ... Lopez, R. (2020). Practical considerations for the evaluation and management of attention deficit hyperactivity disorder (ADHD) in adults. L'Encephale, 46(1), 30-40. https://doi.org/10.1016/j.encep.2019.06.005.

World Health Organization (2019). ICD-11 : International statistical classification of diseases and related health problems. 11th version.

Yen, J.-Y., Liu, T.-L., Wang, P.-W., Chen, C.-S., Yen, C.-F., \& Ko, C.-H. (2017). Association between internet gaming disorder and adult attention deficit and hyperactivity disorder and their correlates: Impulsivity and hostility. Addictive Behaviors, 64, 308-313. https://doi.org/10.1016/j.addbeh.2016.04.024.

Zilberman, N., Yadid, G, Efrati, Y., Neumark, Y., \& Rassovsky, Y. (2018). Personality profiles of substance and behavioral addictions. Addictive Behaviors, 82, 174-181. https://doi.org/10.1016/ j.addbeh.2018.03.007. 